\title{
Modification of borosilicate glass induced by ultraviolet laser illumination
}

\author{
Hirofumi HIDAI*, Souta MATUSAKA*, Akira CHIBA* and Noboru MORITA* \\ * Department of Mechanical Engineering, Chiba University \\ 1-33 Yayoi-cho, Inage-ku, Chiba 263-8522, Japan \\ E-mail: hidai@faculty.chiba-u.jp
}

Received 30 November 2015

\begin{abstract}
There have been many investigations into the changes in the properties of transparent materials, e.g. optical, physical and chemical properties, induced by focused ultrafast laser beams. In this letter, we report the modification of borosilicate glass using an ultraviolet nanosecond laser. A laser beam operating at a wavelength of $266 \mathrm{~nm}$ was focused inside the glass. Interestingly, although penetration depth of the laser beam was only $110 \mu \mathrm{m}$, emission was observed in the glass at the depth of approximately $1100 \mu \mathrm{m}$ after several laser shots. The emission moved toward the light source with further laser illumination, and modification of the glass along the trajectory of the emission was observed. The modified area became deeper with increasing focusing depth. The deepest modified area was located at a depth of approximately $1800 \mu \mathrm{m}$. No clear dependence of the modification on the pulse repetition rate was found; therefore, heat accumulation was not prominent in the modification process. The subsequent etching rate of the modified area was faster than that of the unmodified area. The etching rate in aqueous $\mathrm{KOH}$ was $60 \mu \mathrm{m} / \mathrm{h}$ where continuous modification was obtained. A microchannel with a depth of approximately $400 \mu \mathrm{m}$ and a diameter of approximately $30 \mu \mathrm{m}$ was formed after $10 \mathrm{~h}$ etching.
\end{abstract}

Key words : Ultra-violet laser, Glass, Modification, Optical defect, Etching

\section{Introduction}

Many studies on the processing and modification of transparent materials using focused ultrafast laser beams have been reported, for example, waveguide forming (Gattass and Mazur, 2008, Davis, et. al., 1996), channel fabrication (Gattass and Mazur, 2008, Bellouard, et. al., 2004), and welding (Richter, et. al., 2015). For transparent materials to absorb laser light, non-linear absorption is necessary (Gattass and Mazur, 2008), that is, high peak power and focusing. Different from non-linear absorption, the authors have investigated the modification of glass using the absorption enhancement phenomenon observed in glass at high temperature (Hidai, et. al., 2009, Hidai, et. al., 2010a).

In this letter, we report the modification of borosilicate glass using an ultraviolet nanosecond laser. While the penetration depth of the laser beam in the glass was only $110 \mu \mathrm{m}$, emission was observed in the glass at a depth of approximately $1100 \mu \mathrm{m}$ after several laser shots. Modification of the glass was observed where emission was observed in the material. The emission moved toward the light source with successive laser illumination, and a modified channel was formed along the laser beam path without any relative scanning motion of the laser focus. In-situ high speed camera observation and laser condition influence on modified area, and etching experiments were reported.

\section{Experimental}

The experimental apparatus was similar to that described in our previous reports (Hidai, et. al., 2015a, Hidai, et. al., 2015b, Hidai, et. al., 2010b). Briefly, the laser source was an ultraviolet laser beam (DS20H-266, Photonics Industries International, Inc., NY, USA) operating at a wavelength of $266 \mathrm{~nm}$. A circularly-polarized beam passed through a quarter-wave plate was focused on the sample through a convex lens with a focal length of $30 \mathrm{~mm}$ without any relative 
scanning motion of the laser focus during the laser illumination. The pulse width of the laser was 8 ns. The defocus distance $z_{f}$ was defined as 0 when the focus was matched with top surface of the glass, and was considered to be positive when the focus was set inside the glass. Refraction at the glass surface was not considered in this measurement; therefore, the actual focal positon was located deeper in the glass than the defocus distance $z_{f}$.

Borosilicate glass (Pyrex ${ }^{\circledR}$, Corning 7440, Corning Inc., NY, USA) with a thickness of $10 \mathrm{~mm}$ was used as the workpiece. To observe the drilled hole, a high speed camera (phantom v7.3, Vison Research Inc., NJ, USA) was set orthogonal to the optical axis of the laser beam. The timing of the laser pulse and the shutter of the high speed camera were synchronized using a delay generator (DG645, Stanford Research Systems Inc., CA, USA). A light source was used to illuminate the back face of the sample and a transmitted image was obtained.

The absorption coefficient of the borosilicate glass was measured using thin samples. Transmissivity was measured using a spectrophotometer (V-550, JASCO International Co. Ltd., Tokyo, Japan). For the wet etching, the sample was submerged in $10 \mathrm{M}(35.8 \%)$ aqueous $\mathrm{KOH}(100 \mathrm{~mL})$ solution at $80^{\circ} \mathrm{C}$ and ultrasonic vibration was applied.

\section{Results}

\subsection{Transmittance of the glass}

The measured transmittance of the borosilicate glass is shown in Fig. 1. Because the transmittance of the 10-mm-thick workpiece was too small to measure, 0.1-mm-thick glass was used. The absorption coefficient was calculated from the transmissivity by assuming the surface reflection of the glass was 3.5\%. The transmissivity of the borosilicate glass was $37 \%$, and its absorption coefficient was $90 \mathrm{~cm}^{-1}$ (laser penetration depth is $110 \mu \mathrm{m}$ ) at the wavelength of $266 \mathrm{~nm}$.

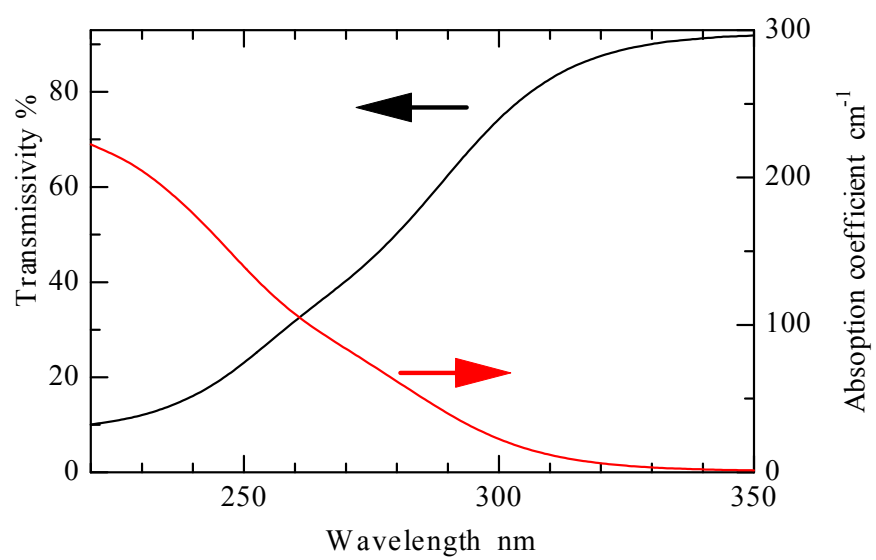

Fig. 1 Transmissivity and absorption coefficient of the borosilicate glass with a thickness of $0.1 \mathrm{~mm}$.

\subsection{In situ observations}

The modification process was observed in situ. The timing of the laser pulse and the high speed camera was synchronized and photographic images of the laser illumination during each pulse were obtained. The results are shown in Fig. 2. No emission was observable until the fourth pulse. Emission was first observed during the fifth pulse at a depth of approximately $1100 \mu \mathrm{m}$, and the location of the emission moved toward the laser source with increasing pulse number. A slight modification of the glass was observed where emission was observed, as marked by the circle in the image of the tenth pulse. During the tenth pulse, emission was observed at the depth of $870 \mu \mathrm{m}$ and continuous modification was observed in the trajectory of the emission (indicated by an arrow). The emission point moved increasingly slowly toward the light source until a depth of approximately $300 \mu \mathrm{m}$. The emission was intermittent when the depth was $\leq 300 \mu \mathrm{m}$; for example, emission was not observed during the $3000^{\text {th }}$ pulse. Finally, the emission reached the glass surface at about the $9800^{\text {th }}$ pulse. After this point, drilling started from the surface, and a hole with a depth of approximately $70 \mu \mathrm{m}$ was formed. No further change was observed with subsequent laser pulses after the formation of the hole. 


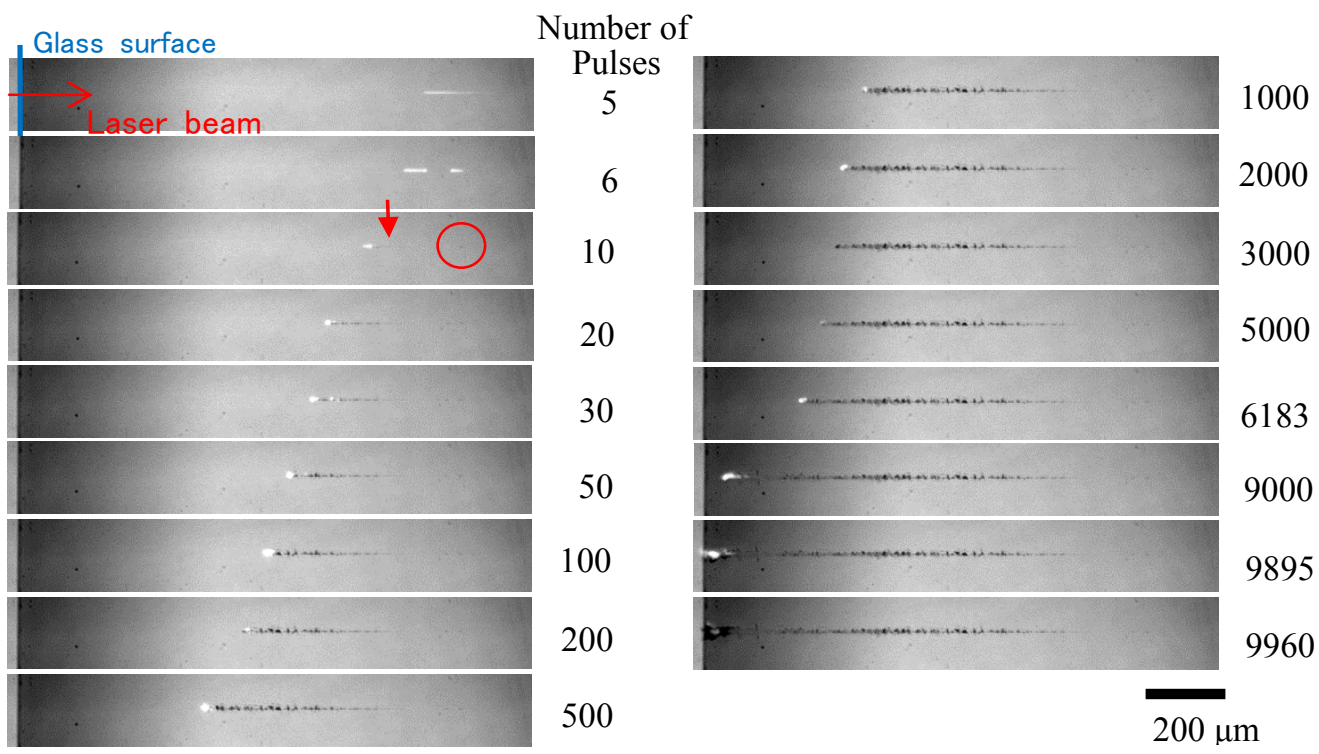

Fig. 2 Visualization of laser-induced emission during laser irradiation process. The pulse energy was set at $100 \mu \mathrm{J}$. The pulse repletion rate was $10 \mathrm{kHz}$ and $z_{f}$ was set at $3000 \mu \mathrm{m}$.

\subsection{Influence of the illumination conditions}

Figure 3 shows the modified areas obtained after 50000 pulses with different focus position. The modified area did not reach the surface of the glass in the case $z_{f}=4500 \mu \mathrm{m}$. When $z_{f}$ was set at $3000 \mu \mathrm{m}$, the modified area reached the surface and a hole was drilled. When $z_{f}$ was $\leq 1500 \mu \mathrm{m}$, only a hole was observed and a modified area could not be distinguished.

The experiments were executed three times under the same conditions. The positions of the modified area are plotted in Fig. 4. The modification was observed within a deeper area with increasing $z_{f}$. When $z_{f}$ was set $\geq 2000 \mu \mathrm{m}$, the modified area is observed in an area deeper than the drilled hole. The lower end of the modified area became deeper with increasing $z_{f}$. The modified area did not reach the surface, when $z_{f}$ was set $\geq 4500 \mu \mathrm{m}$. The upper end of the modified area became deeper with increasing $z_{f}$. The modified area was observed at approximately $1300 \mu \mathrm{m}$ to approximately $1800 \mu \mathrm{m}$ depth at $z_{f}=5500 \mu \mathrm{m}$. No modification was visible when $z_{f}$ was set $\geq 6000 \mu \mathrm{m}$.

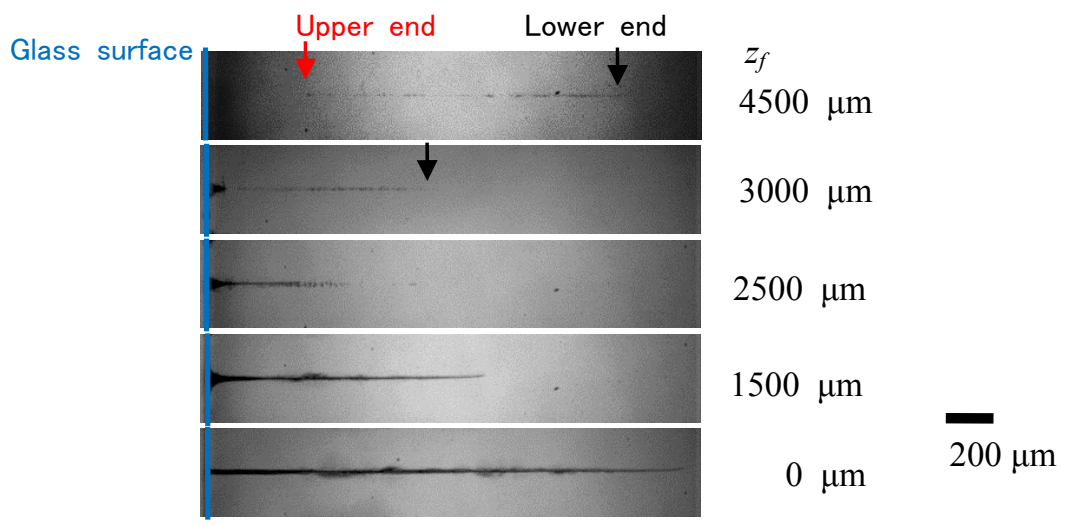

Fig. 3 Photographs of modified and drilled areas obtained at various focal positions. The pulse energy was set at $100 \mu \mathrm{J}$ and the pulse repetition rate was $10 \mathrm{kHz}$. The total number of pulses was 50000 . 


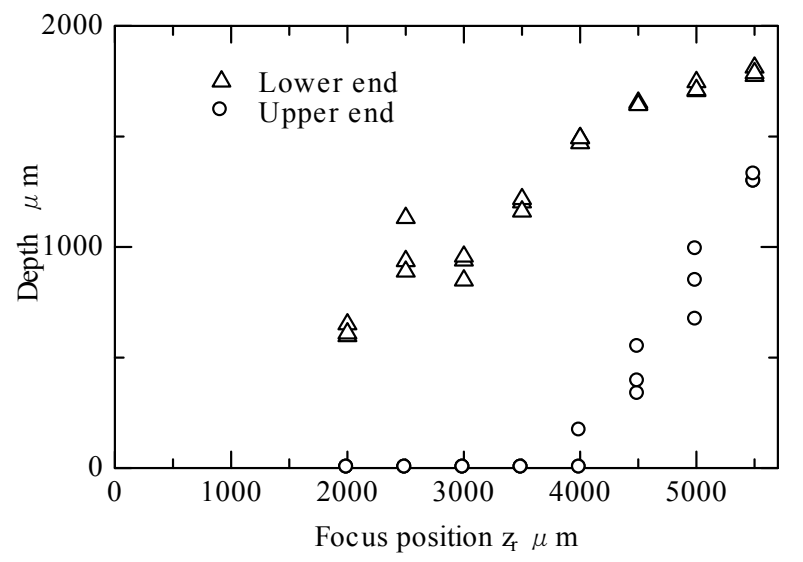

Fig. 4 Influence of focal position on the depth of the modified area. The pulse energy was set at $100 \mu \mathrm{J}$, the pulse repetition rate was $10 \mathrm{kHz}$, and the total number of pulses was 50000 .

In the case of drilling using the same laser, the heat accumulation effect had a drastic influence on the depth of the hole (Hidai, et. al., 2015a). Heat accumulation may also have influenced the modification process. Therefore, the pulse repetition rate was varied. The experiments were executed three times under the same conditions. The depths of the modified area are plotted in Fig. 5. The depth of upper end was small at pulse repetition rates of $1 \mathrm{kHz}, 20 \mathrm{kHz}$, and 25 $\mathrm{kHz}$, but no clear dependence was observed at pulse repetition rates of 5-15 kHz. Hence, the heat accumulation had no significant influence on the modification process.

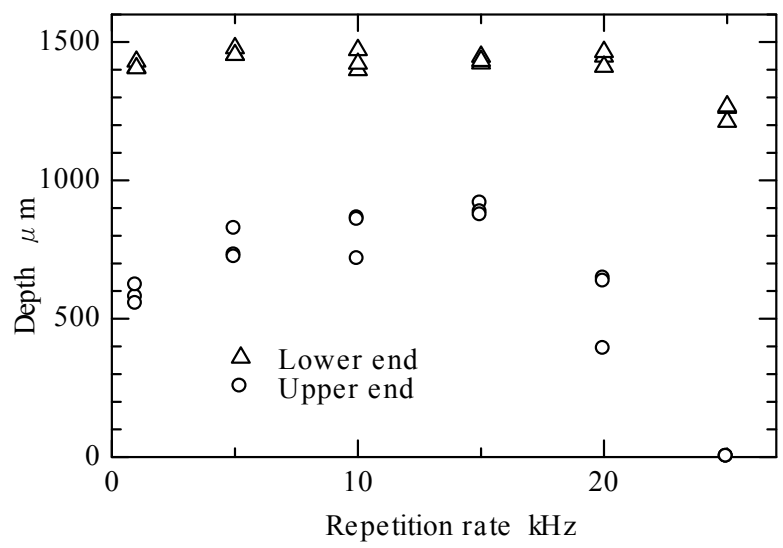

Fig. 5 Influence of the pulse repetition rate. The pulse energy was set at $50 \mu \mathrm{J}$ and $z_{f}$ was set at $3500 \mu \mathrm{m}$. The total number of pulses was 50000 .

The modification induced by different pulse energy is shown in Fig. 6. At pulse energies of $10 \mu \mathrm{J}$ and $20 \mu \mathrm{J}$, the modification did not reach the surface. At $10 \mu \mathrm{J}$, the modified area was difficult to identify because the color change is slight, so the contrast of the image has been enhanced. A thin modified area was observed in the ellipse of the figure. The modification reached the surface at a pulse energy of $50 \mu \mathrm{J}$. At a pulse energy of $100 \mu \mathrm{J}$, the drilled hole was deeper than the continuous modified area, but discontinuous modification was observed in the area deeper than the hole (indicated by the circle) and around the hole (indicated by the arrow). With decreasing pulse energy, the modified area became thinner and lighter in color. 


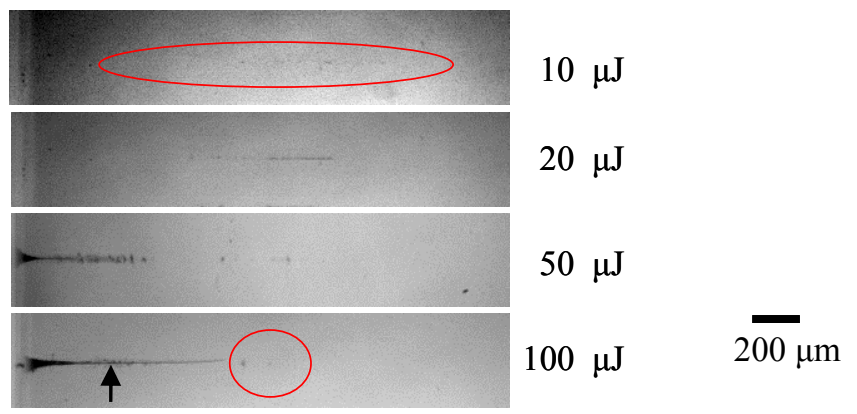

Fig. 6 Photographs of modified and drilled area obtained at various pulse energy. The pulse repetition rate was 10 $\mathrm{kHz}, z_{f}$ was set at $2000 \mu \mathrm{m}$, and the total number of pulses was 50000 .

\subsection{Etching of modified area}

A modified sample was etched with aqueous $\mathrm{KOH}$. The etched sample is shown in Fig. 7. Before etching (Fig. 7(a)), a 200- $\mu$ m-deep drilled hole was observed (bottom of the hole is indicated by the blue arrow). Continuous modification was observed from the bottom of the hole at about $200 \mu \mathrm{m}$ to about $500 \mu \mathrm{m}$, as marked by the ellipse. Discontinuous modification was observed in the area deeper than $700 \mu \mathrm{m}$. After $2 \mathrm{~h}$ etching (Fig. 7(b)), the modified area was etched $80 \mu \mathrm{m}$ from the bottom of the hole (indicated by the circle). Note that etching rate of unmodified glass was $0.25 \mu \mathrm{m} / \mathrm{h}$. The etched area deepened to $300 \mu \mathrm{m}$ after $5 \mathrm{~h}$ etching (Fig. 7(c)). The diameter of the etched area was approximately $30 \mu \mathrm{m}$ and matched the trajectory of the modified area. The etched depth was approximately $400 \mu \mathrm{m}$ after $10 \mathrm{~h}$ etching (Fig. 7(d)). After $50 \mathrm{~h}$ (Fig. 7(e)), the etched depth was $520 \mu \mathrm{m}$ and the diameter of the etched hole was approximately $50 \mu \mathrm{m}$. The etching speed in the radial direction was calculated to be approximately $0.2 \mu \mathrm{m} / \mathrm{h}$ and was almost the same as that of unmodified area. The etched depth is plotted in Fig. 8. The bottom of the hole drilled before etching (marked by the blue arrow in Fig. 7(a)) is defined as the origin. The etching rate was found to be 60 $\mu \mathrm{m} / \mathrm{h}$ at depths of $0-300 \mu \mathrm{m}$ where continuous modification was observed and the etching rate of the modified area was 240 times faster than that of the unmodified area.
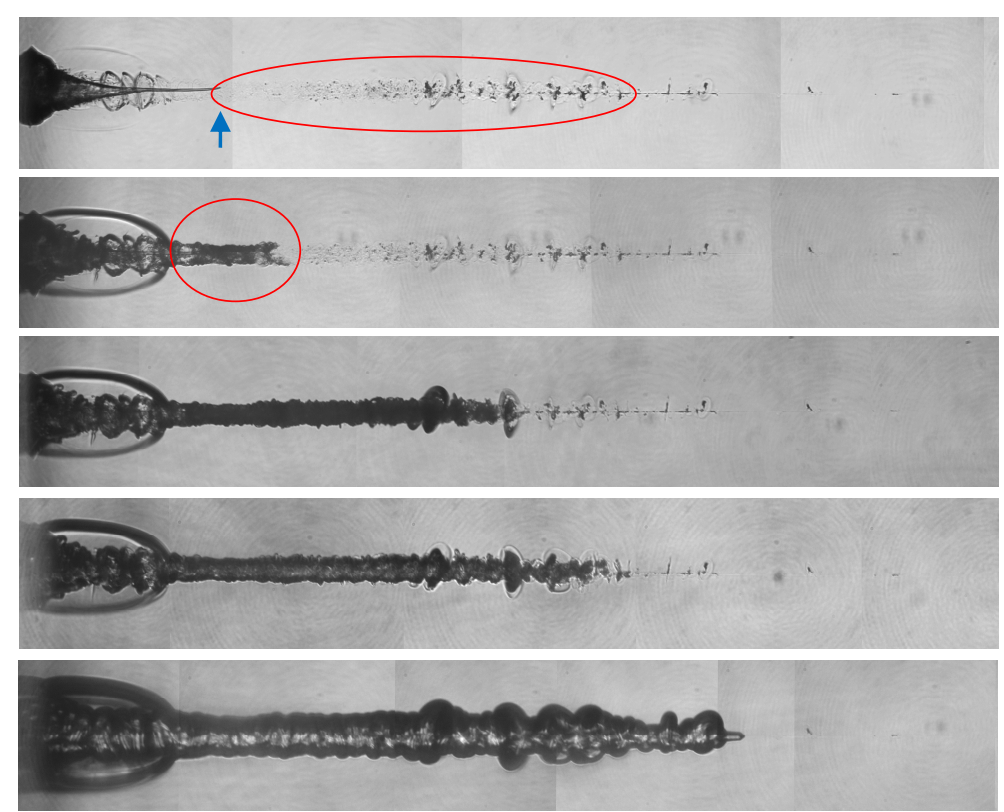

Fig. 7 Hole evolution during the progress of etching in aqueous $\mathrm{KOH}$ at $80{ }^{\circ} \mathrm{C}$. The sample was modified using a pulse repetition rate of $10 \mathrm{kHz}, z_{f}$ of $2000 \mu \mathrm{m}$, and 50000 pulses. (a) before etching

(b) $2 \mathrm{~h}$ etching

(c) 5 h etching

(d) $10 \mathrm{~h}$ etching
(e) $50 \mathrm{~h}$ etching
$100 \mu \mathrm{m}$ 


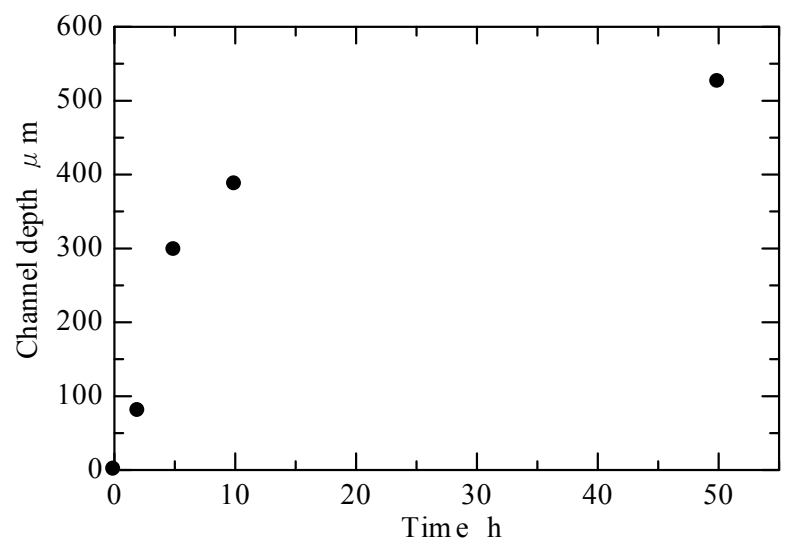

Fig. 8 Channel depth during etching in aqueous $\mathrm{KOH}$ at $80{ }^{\circ} \mathrm{C}$ for sample modified using a pulse repetition rate of $10 \mathrm{kHz}, z_{f}$ of $2000 \mu \mathrm{m}$, and 50000 pulses.

\subsection{Discussion}

The modification mechanism may be considered as follows. First, the fluence where the emission was observed was $2.9 \mathrm{~mJ} / \mathrm{cm}^{2}$ under the beam focused in the glass at a depth of $1100 \mu \mathrm{m}$ with an absorption coefficient of $90 \mathrm{~cm}^{-1}$, spot diameter of $7.3 \mu \mathrm{m}$ (Hidai, et al., 2015a) (same as the calculated beam spot diameter), and reflection at the glass surface of 3.5\%. This value is much smaller than that observed for silica glass ablation (Demos, et. al., 2002, Kucheyev and Demos, 2003). The reason for this is considered to be because the absorption coefficient of borosilicate glass is much larger than that of silica glass.

A similar phenomenon has been reported for the femtosecond laser illumination of silica glass (Hwang, et. al., 2009). Namely, laser illumination below the ablation threshold caused emission in the beam path, the emission became brighter with increasing number of laser shots, and finally ablation began. The laser induced damage was determined to be caused by the creation of NBOHC (non-bridging oxygen hole centers) and ODC (oxygen-deficiency centers), and was not dependent on laser wavelength (Kucheyev and Demos, 2003).

In this work, the ultraviolet laser illumination caused accumulating damage in the glass, which increased its absorption coefficient. After a certain number of illumination pulses, the absorption coefficient of the affected area exceeded the threshold and emission was observed. The surrounding glass was also damaged by the absorption, and so the absorption point moved toward the light source. When the absorption point reached the glass surface, the glass was ablated and drilled. No clear influence of the heat accumulation effect was observed, because no dependence on the pulse repetition rate was seen in Fig. 5. In addition, as shown in Fig. 2, emission ceased and resumed after a certain number of illumination pulses. If the heat accumulation effect were dominant, the cooled absorption point would not be able to resume emission again under the same illumination conditions.

The laser energy at the depth of $1100 \mu \mathrm{m}$ was only $0.005 \%$ of that at the surface of the glass. The fluence where the emission was observed was $2.9 \mathrm{~mJ} / \mathrm{cm}^{2}$ as mentioned above. The fluence at the glass surface was calculated to be 2.5 $\mathrm{J} / \mathrm{cm}^{2}$ under the spot diameter of $71 \mu \mathrm{m}$ (the calculated spot diameter with the defocus distance of $3000 \mu \mathrm{m}$ ). The reason why emission was observed inside the glass but not at the surface was not clarified. Quantitative experiments and accurate estimation of the laser energy in the glass is required.

\section{Conclusion}

We have demonstrated the inner modification of borosilicate glass using an ultraviolet nanosecond laser. Emission was observed inside the glass. The observed emission was located much deeper than the laser penetration depth. The emission moved toward the light source during percussion laser illumination, and modification was observed where emission was observed. The modified area became deeper with increasing focusing depth. The deepest modified area was located at a depth of approximately $1800 \mu \mathrm{m}$. Heat accumulation did not have a prominent effect on the modification process. The etching rate of the modified area was faster than that of unmodified glass, and was $60 \mu \mathrm{m} / \mathrm{h}$ where continuous modification was observed and the etching rate of the modified area was 240 times faster than that of the unmodified area. This characteristic enables deep channel formation in glass. Further investigation to achieve crack 
free modification is required.

\section{References}

Bellouard, Y., Said, A., Dugan, M. and Bado, P., Fabrication of high-aspect ratio, micro-fluidic channels and tunnels using femtosecond laser pulses and chemical etching, Optics Express Vol.12, No.10 (2004), pp. 2120-2129.

Davis, K. M., Miura, K., Sugimoto, N. and Hirao, K., Writing waveguides in glass with a femtosecond laser, Opt. Lett. Vol.21, No.21 (1996), pp. 1729-1731.

Demos, S. G., Staggs, M. and Kozlowski, M. R., Investigation of processes leading to damage growth in optical materials for large-aperture lasers, Appl. Opt. Vol.41, No.18 (2002), pp. 3628-3633.

Gattass, R. R. and Mazur, E., Femtosecond laser micromachining in transparent materials, Nature Photonics Vol.2, No.4 (2008), pp. 219-225.

Hidai, H., Itoh, S., Tokura, H., Nagawasa, S. and Tachikawa, S., High-aspect-ratio Microdrilling with UV Laser Ablation. I - Drilling Holes with an Aspect-ratio of 190 in Borosilicate Glass- J. Jpn. Soc. Precis. Eng. Vol.76, No.10 (2010b), pp. 1161-1165.

Hidai, H., Matsusaka, S., Chiba, A. and Morita, N., Heat accumulation in microdrilled glass from ultraviolet laser ablation, Appl. Phys. A Vol.120, No.1 (2015a), pp. 357-367.

Hidai, H., Matsusaka, S., Chiba, A. and Morita, N., Laser Drilling and Conducting Film Formation of Vias in Silicon, J. Electron. Mater. Vol. 44, No. 12 (2015b), pp. 4928-4932.

Hidai, H., Yoshioka, M., Hiromatsu, K. and Tokura, H., Glass Modification by Continuous-Wave Laser Backside Irradiation (CW-LBI), Appl. Phys. A Vol.96, No.4 (2009), pp. 869-872.

Hidai, H., Yoshioka, M., Hiromatsu, K. and Tokura, H., Structural Changes in Silica Glass by Continuous-Wave Laser Backside Irradiation, J. Am. Ceram. Soc. Vol.93, No.6 (2010a), pp. 1597-1601

Hwang, D., Hiromatsu, K., Hidai, H. and Grigoropoulos, C., Self-guided glass drilling by femtosecond laser pulses, Applied Physics A Vol.94, No.3 (2009), pp. 555-558.

Kucheyev, S. O. and Demos, S. G., Optical defects produced in fused silica during laser-induced breakdown, Appl. Phys. Lett. Vol.82, No.19 (2003), pp. 3230-3232.

Richter, S., Zimmermann, F., Eberhardt, R., Tünnermann, A. and Nolte, S., Toward laser welding of glasses without optical contacting, Applied Physics A Vol.121, No.1 (2015), pp. 1-9. 